\title{
Construction and use of an inexpensive, lightweight free-fall penetrometer: applications to paleolimnological research
}

\author{
Ian S. Spooner ${ }^{1, *}$, Peter Williams ${ }^{2}$ and Kathleen Martin ${ }^{3}$ \\ ${ }^{1}$ Department of Geology, Acadia University, Wolfville, NS, Canada B0P 1X0; ${ }^{2}$ Department of Physics, \\ Acadia University, Wolfville, NS, Canada BOP 1X0; ${ }^{3}$ Environmental Science Program, Acadia University, \\ Wolfville, NS, Canada B0P 1X0; *Author for correspondence (e-mail: ian.spooner@acadiau.ca)
}

Received 3 April 2003; accepted in revised form 13 March 2004

Key words: Paleolimnology, Penetrometer, Physical limnology, Sediment characterisation

\begin{abstract}
This paper describes the construction of an inexpensive, lightweight, free-fall lake sediment penetrometer with application to paleolimnological research. This penetrometer is suitable for use in a variety of fresh water lake settings. Data are collected on a laptop PC, Palm OS handheld, or a Texas Instruments handheld data collection unit and are analysed using commercially available software. The quality of these data are adequate for determining changes in substrate type based on hardness. The unit can also be used to locate sites for optimum penetration of gravity cores and to calibrate sonar records. Addition of up to three optional transducers could expand the capabilities of the unit. Other potential uses include the determination of specific geotechnical properties of the lake sediment including the undrained shear strength.
\end{abstract}

\section{Introduction}

Penetrometers have long been used to measure the physical properties of sediments in situ (Dayal et al. 1975; Chari et al. 1979; Akal and Stoll 2002), most commonly the undrained shear strength and relative density of sea floor sediment (Dayal 1981; Akal and Stoll 2002). Penetrometer data support a variety of applications including seabed classification, geotechnical site investigation, dredging surveys, and naval applications. Two main types of penetrometers are used in lakes or shallow marine settings. In situ designs are, in general, lowered to the lake bed and use the depth of penetration of modified weighted rods to characterise lake sediment properties (Gaugush 1998). Free-fall designs impact the lake bottom and use acceleration and, in some cases, pressure sensors to monitor the sediment response to penetration (Dayal et al.
1975). Several types of free-fall penetrometers exist. Scott (1967) correlated deceleration of a gravity corer with variations in marine sediment characteristics. Thompson and Colp (1970) used a $3^{\prime \prime}$ (76 mm) diameter, 5' (127 mm) long penetrometer for ocean bottom exploration. Penetrometers instrumented with accelerometers have been used to measure acceleration/deceleration and to calculate penetration velocity and depth of penetration by single and double integration of acceleration respectively, with time. These modern penetrometer systems tend to be large and heavy, or as size decreases, expensive. As a result penetrometers have not been used extensively in limnological research and have seen little application in paleolimnology.

The nature and the thickness of post-glacial lacustrine sediments in Atlantic Canada varies widely in lakes located short distances apart 
(Spooner 1998; Stea and Mott 1998) and between basins within individual lakes (Martin et al. 2003). We have noted also that the recovery of sediments by gravity coring varies widely within basins (Martin 2003). The development of the penetrometer described below arose out of the need to quantify variance in the physical characteristics of modern sediment within lake basins, resolve discrepancies in core recovery and lake sediment distribution, and to calibrate sonar records.

This paper discusses the construction and use of an inexpensive, lightweight (electronic), free-fall penetrometer well-suited to use in fresh water lakes. This system weighs approximately $3 \mathrm{~kg}$ (excluding the weight of a computer) and can operate in depths up to $15 \mathrm{~m}$ using either an ice surface or a boat as a stable platform. Greater depths are possible but were not tested in this study. The penetrometer costs about $\$ 540.00$ USD to build excluding computer costs.

\section{Equipment and assembly}

Our penetrometer incorporates commercial components available from Vernier Software and Technology, a science education company. This includes a $25-\mathrm{g}$ accelerometer, a Labpro ${ }^{\mathrm{TM}}$ data collection interface (or optional Go!Link ${ }^{\mathrm{TM}}$ single channel interface), and Logger Pro $3^{\mathrm{TM}}$ analytical software. The accelerometer has a range of $\pm 245 \mathrm{~m} / \mathrm{s} / \mathrm{s}$ and an accuracy of $\pm 2.45 \mathrm{~m} / \mathrm{s} / \mathrm{s}$. The Logger Pro 3 software can be run on a standard desktop or laptop PC or with optional software (Data Pro $^{\mathrm{TM}}$ ) on Palm OS handhelds and Texas Instruments (TI) handhelds. Vernier components and software are described at www.vernier.com. All other parts are readily available through local hardware stores, plumbing outlets, and electrical retailing stores. Some minor machining is also required.

The penetrometer housing is made of $2^{\prime \prime}$ $(5.1 \mathrm{~cm})$ schedule 40 ABS, commonly used for plumbing (Figure 1). The penetrometer head is constructed from barstock aluminium machined to fit the ABS pipe. The radius of the head is $1.18^{\prime \prime}$ $(30 \mathrm{~mm})$. The accelerometer is mounted directly to the penetrometer head using a custom made ' $\mathrm{C}$ ' shaped mounting bracket (Figure 2). All openings on the accelerometer are sealed with silicone to prevent moisture entering the unit. Once the head

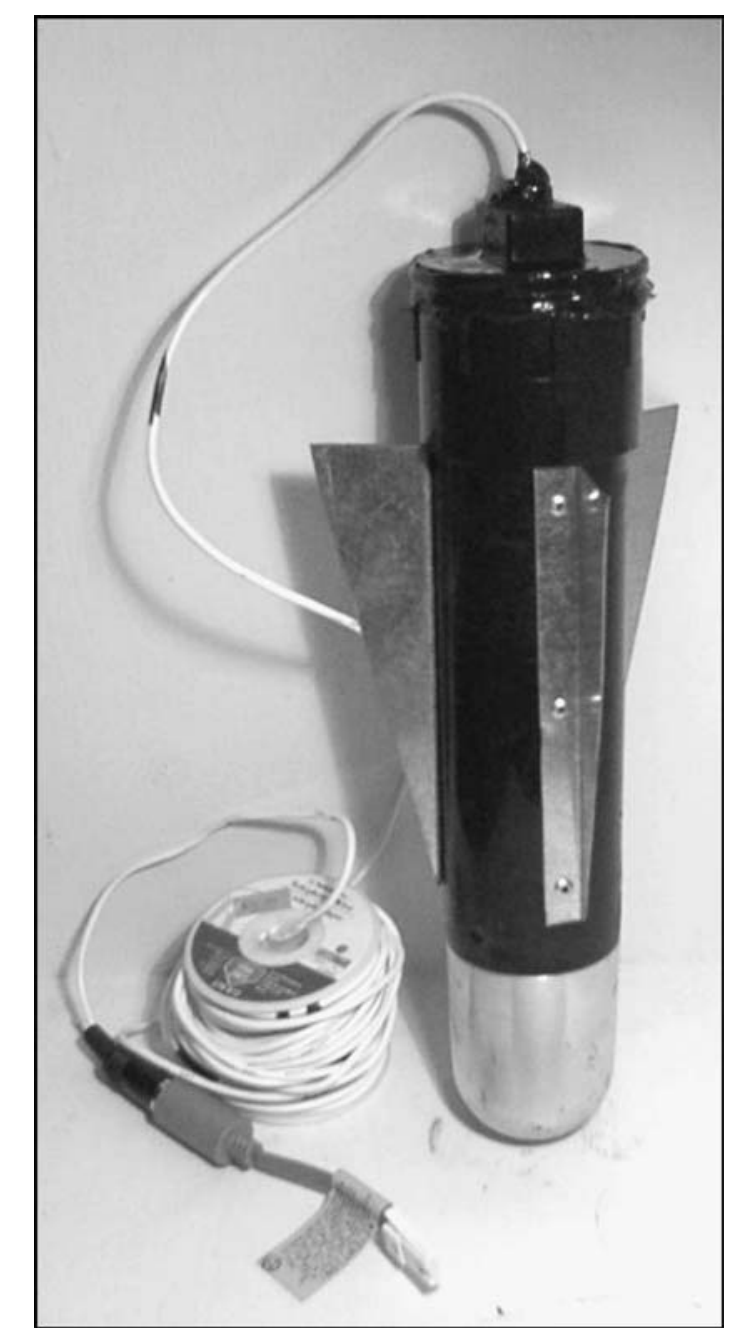

Figure 1. Penetrometer with data acquisition cable. The penetrometer housing is constructed of ABS, the head is aluminium. The design and proportion of the fins (relative to the housing) are based on previous penetrometer designs.

is installed in the ABS housing lead shot is added to increase the mass of the penetrometer. An acrylic epoxy (Envirotex Lite ${ }^{\mathrm{TM}}$ ) was used to completely seal both the lead shot and the accelerometer and was added to a height of $1 \mathrm{~cm}$ above the top of the accelerometer. The sealed penetrometer weighs approximately $2 \mathrm{~kg}$. We use 6 conductor round colour-coded 22 AWG solid telephone wire ( $15 \mathrm{~m}$ length) to carry the accelerometer signal to the Labpro ${ }^{\mathrm{TM}}$ unit. Although this wire is inexpensive it is rather stiff and in cold climate conditions a more flexible stranded wire may be desirable. 


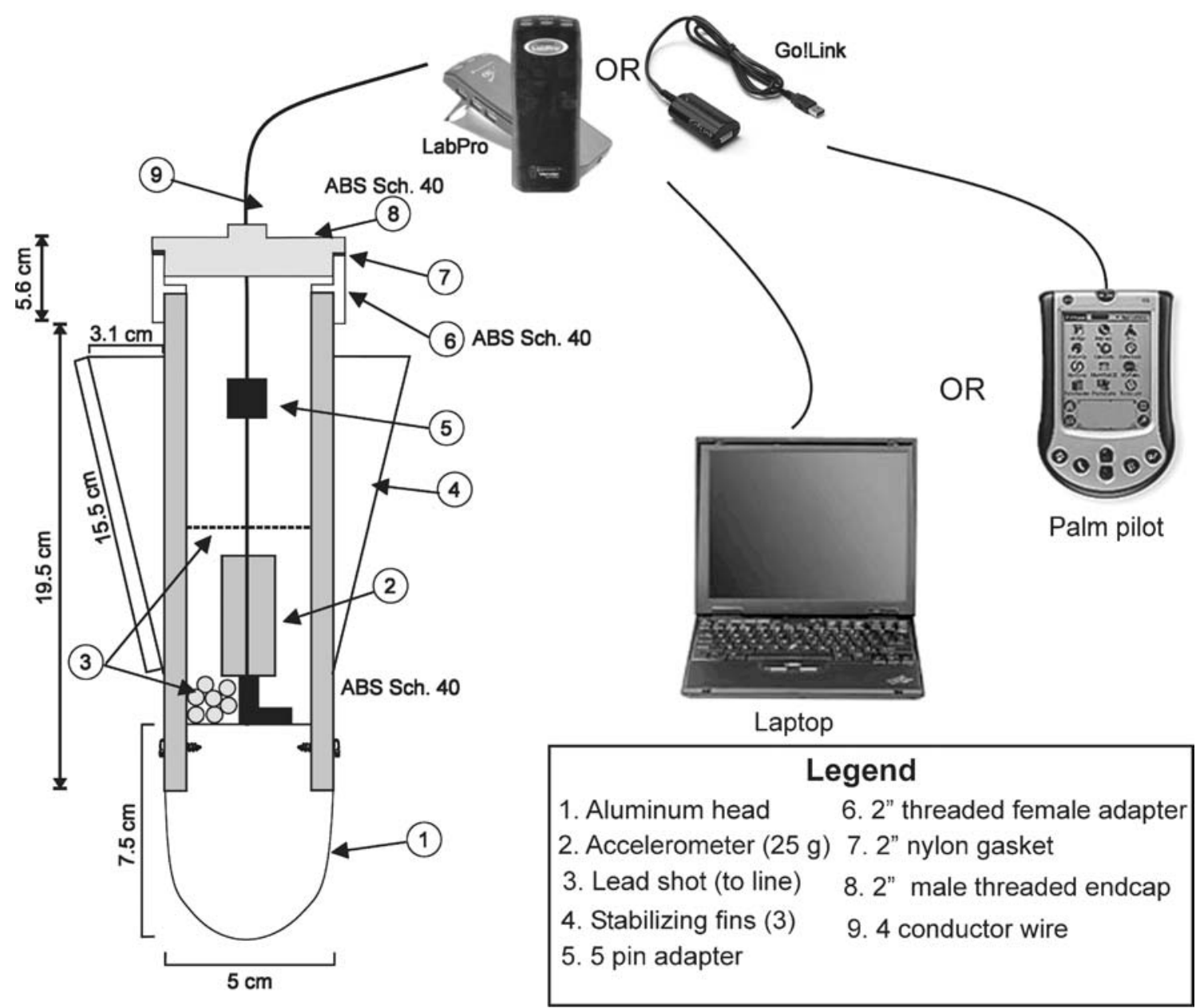

Figure 2. Schematic diagram of penetrometer system. The penetrometer housing is constructed from ABS with a aluminium or brass head and plated steel fins (3). The penetrometer incorporates a $25 \mathrm{~g}$ accelerometer. Data from the accelerometer is transferred to a data collection unit where it is processed and sent for visual display to either a Laptop PC or a Palm unit.

The penetrometer is connected to the Labpro ${ }^{\mathrm{TM}}$ or Go!Link ${ }^{\mathrm{TM}}$ interface which converts the electrical response from the accelerometer to a data stream. We find that a laptop PC is most efficient for displaying and analysing data while in the field. Although Palm OS and TI handheld computers offer a low-weight and low-cost alternative, processing of incoming data was somewhat slower.

\section{Operation}

The drop height required for terminal will vary depending on the weight and material used in the construction of the penetrometer and fluid prop- erties. We found that results were comparable if a consistent drop height was employed even if that height was less than that required for terminal velocity. In practice terminal velocity might be hard to achieve for many settings. In our testing the change in the shape of the acceleration curve produced when the penetrometer contacted the substrate varied considerably with changing substrate composition regardless of the drop height (Figure 3). The data displayed in Figure 3 were generated from a drop height of $2 \mathrm{~m}$.

The method of data analyses and acceleration curve characterisation will vary greatly according to application (Martin 2003). Relative changes in substrate hardness and consistency were quantified by generating a height:width ratio for each accel- 


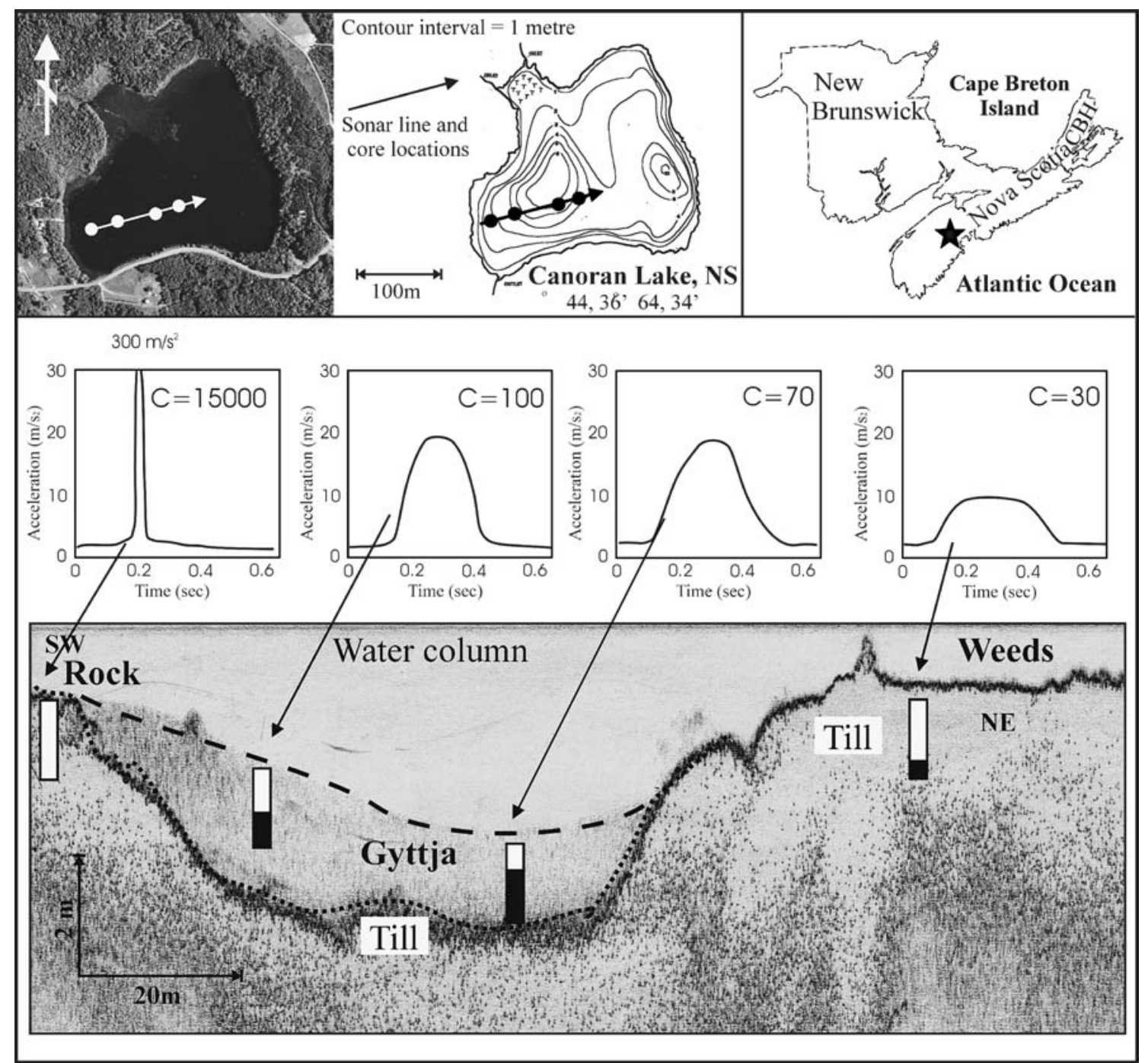

Figure 3. A $50 \mathrm{kHz}$ sonar record from a shallow lake showing representative penetrometer curves for different substrates. Note that each substrate has a characteristic curve shape and height to width ratio. Relative recovery with a Glew gravity corer (Gilbert and Glew 1985) is shown by shaded rectangles, greatest recovery was achieved at site 3 .

eration curve which we called the hardness coefficient $(C)$ :

$$
\begin{aligned}
C= & \text { Height of curve } \\
& / \text { full width at half maximum }
\end{aligned}
$$

The height of the curve was measured from a line connecting inflection points to the apex of the curve. The width was measured at half the maximum height. This is a standard technique used to characterise Gaussian curves which acceleration curves resemble (Bevington and Robinson 2003). As shown in Figure 3 we noted that higher recovery with a Glew gravity corer was generally associated with low $C$ values (Gilbert and Glew 1985). Note however that the lowest $C$ value was obtained when the corer was used over a weed bed.

Data consistency is difficult to measure in natural settings due to changes in substrate composition. However, we evaluated the penetrometer at a $5 \mathrm{~m}$ deep clay lined water reservoir and at a small, gyttja-dominated organic lake (Canoran Lake; Figure 3) using a drop height of $2.0 \mathrm{~m}$ (Figure 4). Thirty tests were conducted at each site; for clarity only maximum and minimum curve height results are shown (Figure 4). For both tests curve shape remained consistent though, as ex- 

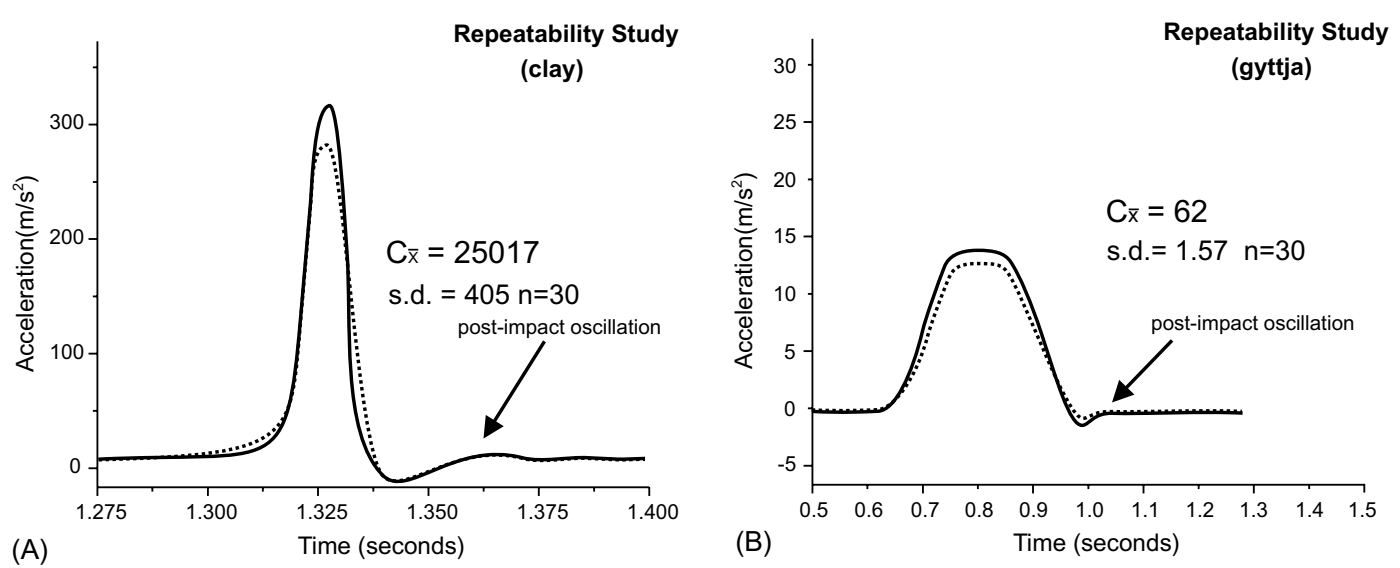

Figure 4. Two examples of acceleration data generated using the freefall penetrometer and a drop height of $2 \mathrm{~m}$. For site A bottom sediment was lodgement till overlain by $5 \mathrm{~cm}$ 's of lake clay (LOI $8 \%$ ). For site B bottom sediment was gyttja (LOI 35\%). At both sites note the consistency of the post-impact oscillation which can be used to quantify the elastic properties of the lake sediment.

pected, peak height fluctuated in response to changes in the substrate composition and density (Figure 4). We note that though a range of $C$ values for the clay substrate were obtained $(C=22,400-25,600)$ these values were more than an order of magnitude greater than those obtained for organic sediment $(C=50-70)$.

\section{Applications: An example}

In our research we have used the penetrometer primarily to determine the relative hardness and consistency of lake-bottom sediment in order to identify optimum coring locations. Sites with very high $C$ values indicate a very hard substrate (till or rock) that may be unsuitable for coring whereas low values indicate sites where greater core recovery is expected. As well, a hard substrate may indicate periods of erosion or nondeposition and the presence of a discontinuous sedimentary record. We have also used the penetrometer to interpret sonar records, especially to characterise the sonar responses to bedrock, inorganic sediment, and organic substrates.

We envisage a number of additional paleolimnological applications. For example, the addition of a pressure transducer would enable the penetrometer to collect simultaneous sounding data. Other sensors (e.g. temperature, dissolved oxygen, conductivity) could also be considered as the Labpro $^{\mathrm{TM}}$ interface (Figure 2) can accept up to four sensors. Finally, a post-impact oscillation is common on acceleration curves for hard substrates (Figure 4). This oscillation is a consequence of the elastic properties of the sediment and, if present can be used to quantify the shear strength of that sediment (cf. Dayal et al. 1975).

\section{Acknowledgements}

This research was funded by Natural Sciences and Engineering Council of Canada (NSERC) and Acadia University. I. Spooner would like to thank K. Simpson for technical assistance. This paper benefited from helpful reviews by D. Hyatt and $\mathbf{J}$. Glew.

The authors have no formal or financial association with Vernier Software and Technology and are not endorsing these products or make claim as to their capabilities, costs, etc. For further information on Vernier Software and Technology please go to www.vernier.com or contact the company at Vernier Software and Technology, 13979 SW Millikan Way, Beaverton, OR 970052886 USA.

\section{References}

Akal T. and Stoll R.D. 2002. Expendable bottom penetrometer for rapid assessment of sea floor geoacoustic and geotechnical properties. Hydro. Int. (March): 33-35.

Bevington P.R. and Robinson D.K. 2003. Data Reduction and Error Analysis for the Physical Sciences. McGraw Hill, New York, 320 pp. 
Chari T.R., Muthukrishnaiah K. and Zeilinski A. 1979. Performance evaluation of a free-fall penetrometer. In: Proceedings of the First Canadian Conference on Marine Geotechnical Engineering, Calgary, AB, pp. 203-210.

Dayal U. 1981. Analysis of free-fall penetrometer data. In: Proceedings of Oceans'81, Boston, USA, pp. 683-687.

Dayal U., Allen J.M. and Jones J.M. 1975. The use of impact penetrometer for the evaluation of the in situ strength of marine sediments. Mar. Geotechnol. 1: 73-89.

Gaugush R.F. 1998. An in situ sediment penetromenter for the characterization of sediment type and bottom dynamic conditions. United States Geological Survey Project Status Report 98-08, 4 pp. http://www.umesc.usgs.gov/reports publications/psrs/psr_1998_08.htm.

Gilbert R. and Glew J. 1985. A portable percussion coring device for lacustrine and marine sediments. J. Sediment. Petrol. 55: 607-608.

Martin K. 2003. Physical evolution of Canoran Lake Nova, Scotia. Focus on lake sediment dynamics. BSc Thesis, Acadia University, $114 \mathrm{pp}$
Martin K., Spooner I.S. and Williams P. 2003. The nature and distribution of postglacial sedimentation in shallow, organic lakes. In: Northeastern Geological Society of America - Atlantic Geoscience Society Joint Meeting, March 27-29, 2003 Halifax, NS. Abstracts with Programs, p. 72.

Scott R.F. 1967. In place measurements of the ocean floor soils by accelerometer. In: Proceedings of the Conference on Civil Engineering in the Oceans-1, ASCE San, Francisco, California, pp. 419-444.

Spooner I.S. 1998. Changes in lake-sediment stratigraphy associated with late glacial climate change: Examples from western Nova Scotia. Atlantic Geol. 34: 229-240.

Stea R.R. and Mott R.J. 1998. Deglaciation of Nova Scotia: Stratigraphy and chronology of lake sediment cores and buried peat sections. Geogr. Phys. Quatern. 52: 3-21.

Thompson L.J. and Colp J.L. 1970. Application of earth penetration technology to ocean bottom penetration. In: 2nd Offshore Technology Conference, OTC 1203. 1: 511576. 